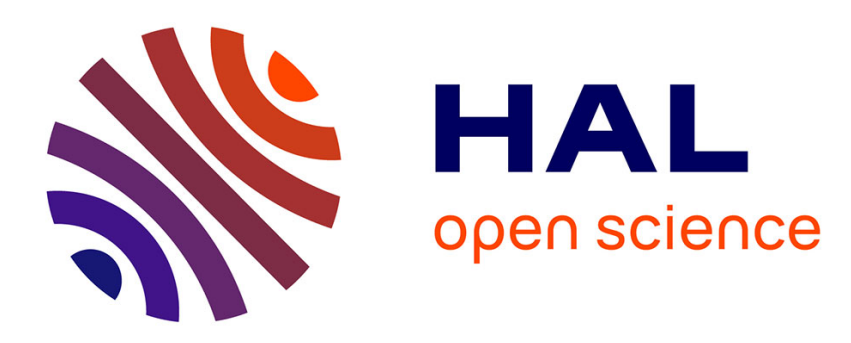

\title{
Modelling of Silicon Oxynitridation by Nitrous Oxide using the Reaction Rate Approach
}

Christophe Krzeminski

\section{To cite this version:}

Christophe Krzeminski. Modelling of Silicon Oxynitridation by Nitrous Oxide using the Reaction Rate Approach. Journal of Applied Physics, 2013, 114, pp.224501. 10.1063/1.4839675 . hal-00923920

\section{HAL Id: hal-00923920 \\ https://hal.science/hal-00923920}

Submitted on 5 Jan 2014

HAL is a multi-disciplinary open access archive for the deposit and dissemination of scientific research documents, whether they are published or not. The documents may come from teaching and research institutions in France or abroad, or from public or private research centers.
L'archive ouverte pluridisciplinaire HAL, est destinée au dépôt et à la diffusion de documents scientifiques de niveau recherche, publiés ou non, émanant des établissements d'enseignement et de recherche français ou étrangers, des laboratoires publics ou privés. 
Modelling of Silicon Oxynitridation by Nitrous Oxide using the Reaction Rate

\section{Approach $^{\mathrm{a})}$}

Christophe Dominique KRZEMINSKI

IEMN-UMR-8520 -Départment ISEN - 41 Boulevard Vauban 59046 Lille Cedex -

France

(Dated: January 5, 2014)

Large technological progress in oxynitridation processing leads to the introduction of silicon oxynitride as ultra-thin gate oxide. On the theoretical side, few studies have been dedicated to the process modelling of oxynitridation. Such an objective is a considerable challenge regarding the various atomistic mechanisms occurring during this fabrication step. In this article, some progress performed to adapt the reaction rate approach for the modelling of oxynitride growth by a nitrous ambient are reported. The Ellis and Buhrman's approach is used for the gas phase decomposition modelling. Taking into account the mass balance of the species at the interface between the oxynitride and silicon, a minimal kinetic model describing the oxide growth has been calibrated and implemented. The influence of nitrogen on the reaction rate has been introduced in an empirical way. The oxidation kinetics predicted with this minimal model compares well with several experiments.

\footnotetext{
a) christophe.krzeminski@isen.fr
} 


\section{INTRODUCTION}

Silicon oxynitridation is a routinely fabrication process used by the semiconductor industry to replace the classical silicon dioxide in the gate processing of logic transistor devices even for the most advanced technological node ${ }^{1,2}$. The main interest of oxynitridation is related to the nitrogen incorporation at the interface which improves i) the silicon interface passivation (with the reduction of electrically active defects or traps) ${ }^{3}$ ii) the breakdown properties $^{4}$ and iii) the reliability ${ }^{5}$. Several methods reported the fabrication of silicon oxynitride $\left(\mathrm{SiO}_{x} \mathrm{~N}_{y}\right)$. Most of them are based on different ambients such as : (i) ammonium $\left(\mathrm{NH}_{3}\right)$ nitridation ${ }^{6,7}$, (ii) nitric oxide $(\mathrm{NO})^{8-11}$ and (iii) oxidation by nitrous oxide $\left(\mathrm{N}_{2} \mathrm{O}\right)^{12-15}$. Despite the relatively low concentration of nitrogen incorporated, the oxides grown in a nitrous oxide ambient are known to generate a gate oxide with an excellent quality and reliability ${ }^{16}$.

A better understanding of the $\mathrm{O}_{2}$ and nitrogen distribution during the different processes is necessary for gate stack optimization. To date, for classical dry or wet silicon oxidation, the phenomenological model of Deal and Grove remains used to describe the oxide growth kinetics in a process simulator ${ }^{17}$. Assuming a steady state for the reaction between the oxidizing agent and silicon, Deal and Grove deduced that the oxide growth can simply be described by this analytical linear-parabolic relationship as a function of the oxidation time. In the specific case of $\mathrm{N}_{2} \mathrm{O}$ oxynitridation, only preliminary studies are available in the literature ${ }^{18-20}$. For example, some models propose a modified version of the Deal and Grove $^{18}$ or Massoud's model ${ }^{19}$ to take into account the influence of nitrogen on oxidation kinetics. A fully parametric approach was also suggested in order to fit the kinetics by an empirical time dependent law ${ }^{20}$. However, nobody has been proposed a physical model able to describe the nitrogen incorporation and its profile engineering ${ }^{21-24}$. The main purpose of this paper is to present some progress towards this objective with the build-up of an extended oxynitridation model and the calibration of a minimal one able to describe the oxide growth. 


\section{GAS PHASE DECOMPOSITION MODELLING}

Initially, $\mathrm{N}_{2} \mathrm{O}$ is the unique constituent of the oxidizing gas phase. The various species concentration generated during the decomposition of the $\mathrm{N}_{2} \mathrm{O}$ molecule are needed. Several approaches were published ${ }^{25-27}$ in order to simulate the gas phase decomposition of the $\mathrm{N}_{2} \mathrm{O}$ molecule. These three models are based on the chemistry of $\mathrm{NO}_{x}$ compounds which are intensively studied in another research domain (air pollution and combustion reactions). The main differences between these different models is the description level and the number of reactions considered to describe the decomposition. Up to eighty different chemical reactions can be formulated for the most complex one ${ }^{25}$. The approach of Ellis and Buhrman ${ }^{27}$ has been preferred since the $\mathrm{N}_{2} \mathrm{O}$ gas phase decomposition can be simulated with a simple eight reaction scheme.

\section{A. Reaction Scheme}

The next system of equations (1) described the following reaction scheme:

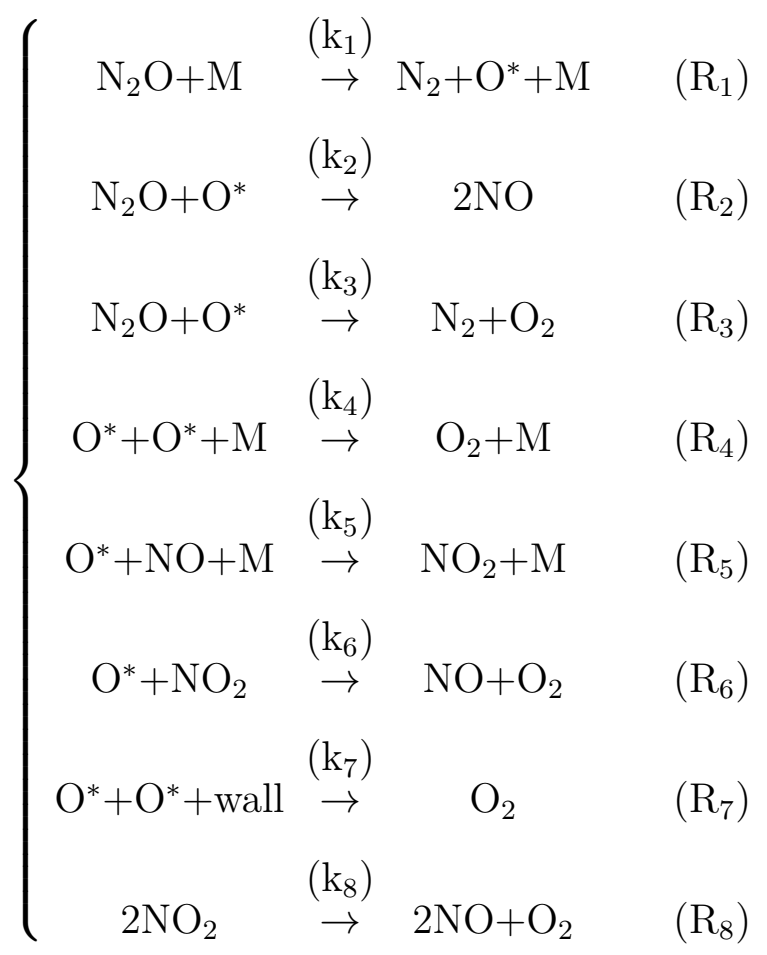




$$
\text { where } \mathrm{M}=\mathrm{N}_{2} \mathrm{O}+\mathrm{N}_{2}+\mathrm{O}_{2}+\mathrm{NO}+\mathrm{NO}_{2}+\mathrm{O}^{*}
$$

Factor $M$ corresponds to the different collision partners and is equal to the sum of the different species in the furnace. During the decomposition process, five different compounds are generated: molecular nitrogen $\left(\mathrm{N}_{2}\right)$, molecular oxygen $\left(\mathrm{O}_{2}\right)$, nitric oxide $(\mathrm{NO})$, nitrogen dioxide $\left(\mathrm{NO}_{2}\right)$ and atomic oxygen $\left(\mathrm{O}^{*}\right)$. At the beginning of the reaction $\left(\mathrm{R}_{1}\right)$, the $\mathrm{N}_{2} \mathrm{O}$ molecule activates the decomposition. This reaction is the most important one since it initiates the $\mathrm{N}_{2}$ decomposition : the main products created by the first reaction $\left(\mathrm{R}_{1}\right)$ are $\mathrm{N}_{2}$ and $\mathrm{O}^{*} . \mathrm{O}^{*}$ is the most important one in the reaction scheme since this radical is involved in six reactions out of eight. The two reactions $\left(R_{2}\right.$ and $\left.R_{3}\right)$ increase the decomposition and lead to the creation of new products $\left(\mathrm{NO}, \mathrm{O}_{2}\right.$ and $\left.\mathrm{N}_{2} \mathrm{O}\right)$. At the end of the reaction, only three main compounds remain : $\mathrm{N}_{2}, \mathrm{O}_{2}$ and NO. Each reaction $(x: 1 \rightarrow 8)$ is activated by a rate described by an Arrhenius law:

$$
k_{x}=k_{0 x} \exp \left(\frac{-E_{x}}{k_{b} T}\right)
$$

where $x$ corresponds to the reaction $\mathrm{R}_{x} . \mathrm{E}_{x}$ is the activation energy and $\mathrm{k}_{0 x}$ is the pre-exponential factor. The various concentrations are given in $\mathrm{mol} / \mathrm{cm}^{3}$. As shown in figure (1), the reaction rate of reaction $\mathrm{R}_{1}$ is defined by three different Arrhenius laws. Each temperature range is described in table I. However, the other reaction rates from $\left(\mathrm{k}_{2}\right.$ to $\left.\mathrm{k}_{8}\right)$ follow more classical expressions as shown in table II.

The evolution for each species is described by the reaction rate approach which postulates that for a general second order reaction :

$$
\mathrm{a}[\mathrm{A}]+\mathrm{b}[\mathrm{B}] \stackrel{k(T)}{\rightarrow} \mathrm{c}[\mathrm{C}]+\mathrm{d}[\mathrm{D}]
$$

the decay rate of the $[A]$ specie is given by :

$$
\frac{d[A]}{d t}=-a k(T)[A]^{a}[B]^{b} .
$$


Applying this framework with the previous reaction scheme described by equation $(1),\left(\mathrm{R}_{1}\right)$ $\rightarrow\left(\mathrm{R}_{8}\right)$ leads to a system of six coupled differential equations able to simulate the evolution of the different species:

$$
\begin{aligned}
& \frac{\partial\left[N_{2} O\right]}{\partial t}=-k_{1}\left[N_{2} O\right][M]-\left(k_{2}+k_{3}\right)\left[N_{2} O\right]\left[O^{*}\right] \\
& \frac{\partial[N O]}{\partial t}=2 k_{2}\left[N_{2} O\right]\left[O^{*}\right]-k_{5}[O][N O][M] \\
& +k_{6}\left[N O_{2}\right]\left[O^{*}\right]+2 k_{8}\left[N O_{2}\right]\left[N O_{2}\right] \\
& \frac{\partial\left[N_{2}\right]}{\partial t}=k_{1}\left[N_{2} O\right][M]+k_{3}\left[N_{2} O\right]\left[O^{*}\right] \\
& \frac{\partial\left[O^{*}\right]}{\partial t}=k_{1}\left[N_{2} O\right][M]-\left(k_{2}+k_{3}\right)\left[N_{2} O\right]\left[O^{*}\right] \\
& -\left(k_{4}[M]+k_{7}\right)\left[O^{*}\right]^{2}-k_{5}\left[O^{*}\right][N O][M] \\
& -k_{6}\left[\mathrm{O}^{*}\right]\left[\mathrm{NO}_{2}\right] \\
& \frac{\partial\left[O_{2}\right]}{\partial t}=k_{3}\left[N_{2} O\right]\left[O^{*}\right]+\left(k_{4}[M]+k_{7}\right)[O]^{2} \\
& +k_{3}[O]\left[N_{2} O\right]-k_{5}[O][N O][M] \\
& +k_{6}\left[\mathrm{O}^{*}\right]\left[\mathrm{NO}_{2}\right]+k_{8}\left[\mathrm{NO}_{2}\right]^{2} \\
& \frac{\partial\left[N O_{2}\right]}{\partial t}=k_{5}\left[O^{*}\right][N O][M]-k_{6}\left[O^{*}\right]\left[N O_{2}\right] \\
& -2 k_{8}\left[N O_{2}\right]^{2} \text {. }
\end{aligned}
$$

A five order Runge-Kutta algorithm using an adaptive step was used in order to solve the equations system ${ }^{28}$. The main concern with the numerical resolution of this system is that the reaction rate of $R_{5}$ is very high and thus a very short initial time-step is necessary ( $\sim$ $1 \mathrm{ps}$ ). An initial ambient made of pure $\mathrm{N}_{2} \mathrm{O}$ at a concentration of $1 \times 10^{-04} \mathrm{~mol} / \mathrm{cm}^{3}$ was also considered. 


\section{B. Results}

The $\mathrm{N}_{2} \mathrm{O}$ half-life time as function of the furnace temperature is reported in figure (2). It corresponds to the time necessary to reach $50 \%$ of decay in the initial gas phase concentration. Is is clear that the decomposition is very fast at a high temperature (less than 0.1 $\mathrm{ms}$ at $1200^{\circ} \mathrm{C}$ ) but increases linearly with decreasing temperature. For example, at $750^{\circ} \mathrm{C}$, the half-time life is closed to 20s. A large time indicating that the decomposition could not be complete at the end of the temperature ramp-up during furnace oxynitridation. The half-time life value of the $\mathrm{N}_{2} \mathrm{O}$ molecule extracted is directly comparable to those of Tobin et $a l .{ }^{29}$ obtained by a simple two-reaction scheme. The three discontinuities of the half-life time are directly linked to the variation assumed for reaction rate $k_{1}$ for the reaction $R_{1}$.

Next, the evolution at $1200^{\circ} \mathrm{C}$ of the different species $\left(\mathrm{N}_{2} \mathrm{O}, \mathrm{N}_{2}, \mathrm{O}_{2}, \mathrm{O}^{*}, \mathrm{NO}, \mathrm{NO}_{2}\right)$ during decomposition is reported in figure (2). The $\mathrm{N}_{2} \mathrm{O}$ concentration decay is very effective between $\left[10^{-4}-10^{-2}\right] \mathrm{s}$ which is in agreement with the value of the half-life time $\left(0.1 \mathrm{~ms}\right.$ at $\left.1200^{\circ} \mathrm{C}\right)$ previously calculated. The first compounds formed around $10^{-7} \mathrm{~s}$ are $\mathrm{O}^{*}$ and $\mathrm{N}_{2}$ through reaction $R_{1}$. As shown in figure $(3)$, the $\mathrm{O}^{*}$ concentration increases slowly and reaches a maximum at $10^{-5} \mathrm{~s}$. At this time, reactions $\mathrm{R}_{3}$ and $\mathrm{R}_{2}$ do not contribute to the $\mathrm{N}_{2} \mathrm{O}$ decomposition since $\mathrm{O}^{*}$ is in sufficient concentration to create mostly $\mathrm{N}_{2}, \mathrm{O}_{2}$ and $\mathrm{NO}$ compounds. It can be observed that reaction $R_{2}$ is the main source of nitric oxide NO. During this step, a small amount of $\mathrm{NO}_{2}$ is created. The $\mathrm{NO}_{2}$ concentration reaches its maximum at $5 \cdot 10^{-3} \mathrm{~s}$. The decomposition of this molecule increases the amount of NO concentration generated through reactions $\mathrm{R}_{6}$ and $\mathrm{R}_{8}$. These results stress the key role of $\mathrm{O}^{*}$ in the generation of NO.

Finally, the gas phase steady state composition as a function of the furnace temperature is given in figure (4) since the remaining products play a major role in the oxynitridation process. A key result is that the final ambient contains only three different species: $\mathrm{N}_{2}, \mathrm{O}_{2}$ and $\mathrm{NO}$ and is not so far from a dry oxidation diluted with nitrogen $(\mathrm{N})$. The amount of NO generated is generally very small (less than $3 \%$ of the ambient). A zoom provided by figure (5) on the NO concentration increase shows that a high temperature is beneficial. 


\section{A COMPACT MODEL FOR $\mathrm{N}_{2} \mathrm{O}$ OXYNITRIDATION}

Several publications highlight that the reaction rate approach is of particular interest in order to provide a more physical alternative to the Deal and Grove model for ultra-thin oxidation $^{30-32}$. The basic idea governing this approach is to estimate the different species during the reaction with the Si substrate in order to overcome the main assumption of the Deal and Grove model ( ie stationarity and a sharp interface). In this framework, the development of a compact model able to simulate the $\mathrm{N}_{2} \mathrm{O}$ oxynitridation step is presented. First, the system considered is specified. Next, the main reactions with the Si substrate during oxynitridation and their mathematical formulation is reported.

\section{A. System description}

A schematic of the system considered is reported in figure (6). The Si substrate can be viewed as a Si monolayers assembly in interaction with the gas phase. In order to simulate an ultra-thin oxidation, a one dimensional mesh matching the oxidation of the [100] silicon surface is assumed. This means that the vertical resolution of the mesh corresponds to the distance between two Si planes $(1.35 \AA)$. The first node is associated to the gas phase. The film growth is restricted to the vertical direction. Thanks to the previous results concerning the gas phase decomposition, it can be reasonably assumed that the decomposition of the $\mathrm{N}_{2} \mathrm{O}$ gas is complete and that the ambient is composed of $\mathrm{O}_{2}, \mathrm{~N}_{2}$ and $\mathrm{NO}^{33}$. In the substrate, two silicon based species: $\mathrm{Si}$ and $\mathrm{SiO}_{2}$ are considered. A new specie $\mathrm{SiN}^{34}$ was introduced to take the formation between $\mathrm{N}$ and Si into account. In order to describe the evolution of the species $j$ (where $j=\mathrm{O}_{2}, \mathrm{NO}, \mathrm{Si}, \mathrm{SiO}_{2}, \mathrm{SiN}$ ), their normalized concentration $n_{j}$ can be defined by :

$$
n_{j}(x, y, t)=\frac{C_{j}(x, y, t)}{C_{j}^{0}}
$$

where $C_{j}$ corresponds to the planar concentration in units of the number of atoms per surface unit, and $C_{j}^{0}$ is the maximum possible concentration in the plane. $n_{j}$ corresponds to the layer coverage. For example, a value of 1 for $n_{S i}$, means that the layer coverage is complete and corresponds to a concentration of $0.9110^{15} \mathrm{at} / \mathrm{cm}^{2}$ of silicon. 


\section{B. Main reactions with the silicon substrate}

Based on the previous result of the gas phase decomposition, the $\mathrm{N}_{2} \mathrm{O}$ oxynitridation process is approximated as shown in figure 7 as mostly a dry oxidation process with in parrallel an oxynitridation step made by nitric oxide. In a previous work ${ }^{32}$, a model based on the diffusion-reaction rate approach for dry oxidation is reported. In several aspects, the physical picture adopted is not so far from the Deal and Grove model. Molecular oxygen $\mathrm{O}_{2}$ diffuses in silicon dioxide by a thermally activated process and the hydrostatic pressure influence is neglected ${ }^{35}$. Thus, the reaction between silicon and oxygen is described with this chemical equation (13):

$$
\mathrm{Si}+\mathrm{O}_{2} \rightarrow \mathrm{SiO}_{2} \quad \text { (Molecular oxidation) }
$$

It could be noticed that in the reaction rate approach framework, the oxidation reaction does no take place strictly at the $\mathrm{Si} / \mathrm{SiO}_{2}$ interface as postulated by the Deal and Grove model $^{17}$. In agreement with some isotopic characterisation ${ }^{36}$, the reaction region is not strictly sharp and can defined in our framework by the overlap between oxygen and silicon concentration. This approach enable probably a better description of the complex

The situation is however much more complex than dry oxidation since the presence of nitric oxide (NO) in the gas phase increases the overall complexity. The oxynitridation process could be see as a parrallel oxidation mechanism ${ }^{37}$ but with molecular oxygen and nitric oxide. It is assumed here that the nitrous molecule diffuses from the gas phase to the $\mathrm{SiO}_{2}$. The NO decomposition is supposed to takes place at the silicon interface where a significant Si concentration is present and generates both atomic $\mathrm{N}^{*}$ and $\mathrm{O}^{*}$ :

$$
N O \rightarrow N^{*}+O^{*} \quad \text { (Atomic nitrogen generation) }
$$

Theoretically, three different reactions (oxidation, nitridation and nitrogen removal) have to be considered in the reactive region :

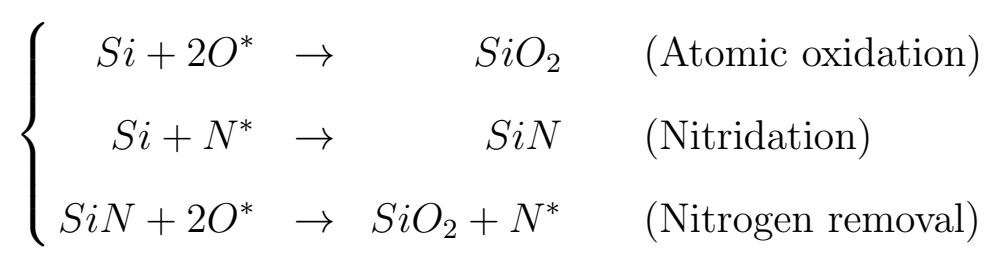


The first one corresponds to the $\mathrm{Si}$ oxidation with $\mathrm{O}^{*}$. Two $\mathrm{O}^{*}$ atoms are necessary in order to generate $\mathrm{SiO}_{2}$. Since O* is a very reactive chemical specie ${ }^{38}$, this reaction is probably the most dominant one. The second one is a key mechanism since it corresponds to the Si nitridation and the formation of SiN species in presence of atomic $\mathrm{N}^{*}$. It has been observed that mostly Si-N bonds are created by nitrous or nitric oxynitridation ${ }^{39}$. Finally, the third one describes the $\mathrm{N}$ removal ${ }^{40}$. The presence of $\mathrm{O}^{*}$ is known to remove the $\mathrm{N}$ incorporated in the and to generate silicon dioxide $\mathrm{SiO}_{2}$. An intense competition between the last two mechanisms is often put forward to explain the low $\mathrm{N}^{*}$ incorporation into $\mathrm{SiO}_{x} \mathrm{~N}_{y}{ }^{40}$ and the fact that classical oxidation remains the main mechanism in $\mathrm{N}_{2} \mathrm{O}$ oxynitridation.

\section{The minimal model}

A minimal model for $\mathrm{N}_{2} \mathrm{O}$ oxynitridation process considering the oxidation by $\mathrm{O}_{2}$ alone has been set up in the framework of the reaction rate approach. The influence of $\mathrm{N}$ is taken into account indirectly. The study of the gas phase decomposition shows that the steady state ambient is mostly composed of $\left(\mathrm{O}_{2}\right)$ and $\mathrm{N}_{2}$ (inert). This result can be used in order to build a first order minimal model. As shown in figure (5), the nitric oxide (NO) molecule in the gas phase has been estimated to be less than $4 \%$ in our simulation. All the reactions between the products from NO decomposition and the Si atoms can be neglected in first order to build-up a compact model :

$$
\left\{\begin{array}{lll}
\frac{\partial n_{\left[\mathrm{O}_{2}\right]}}{\partial t} & =\nabla\left(D \nabla n_{\left[\mathrm{O}_{2}\right]}\right)-k_{[N]} n_{\left[\mathrm{O}_{2}\right]} n_{[\mathrm{Si}]} \\
\frac{\partial n_{[\mathrm{Si}]}}{\partial t} & = & -k_{[N]} n_{\left[\mathrm{O}_{2}\right]} n_{[S i]} \\
\frac{\partial n_{\left[\mathrm{SiO} O_{2}\right]}}{\partial t} & = & k_{[N]} n_{\left[\mathrm{O}_{2}\right]} n_{[S i]}
\end{array}\right.
$$

This model is close to the previous dry oxidation model related to the reaction rate approach $^{30,32}$ except that the reaction rate $\mathrm{k}_{[N]}$ governing the reaction between $\mathrm{O}_{2}$ and $\mathrm{Si}$ is dependent on $\mathrm{N}$ concentration. Since the nitrogen peak is experimentally strongly localized at the $\mathrm{Si} / \mathrm{SiO}_{x} \mathrm{~N}_{y}$ interface, a possible influence on $\mathrm{O}_{2}$ diffusivity has been neglected. The solubility limits of $\mathrm{O}_{2}$ have also been neglected in this work. It would probably be of interest to refine the model by introducing a limited solubility effect ${ }^{41}$ since it impacts the definition of the reaction region. The same Arrhenius law fitted on several dry oxidation experiments 
in a previous work ${ }^{32}$ has been used :

$$
D=D_{0} \cdot \exp \left(\frac{-E_{D}}{k_{B} T}\right)
$$

with an activation energy of $E_{D}=2.22 \mathrm{eV}$ and a prefactor $D_{0}=1.291 \times 10^{11} \mathrm{~nm}^{2} / \mathrm{s}$.

\section{Physical origin of the influence of nitrogen on the oxide growth}

The influence of doping on the oxide growth rate has been largely studied in the literature. The mostly accepted physical picture is from the Ho and Plummer ${ }^{42,43}$ where the linear growth rate of the Deal and Grove theory is directly related to the concentration of point defects present at the $\mathrm{Si} / \mathrm{SiO}_{2}$ interface. The main defect considered is the Si vacancy since it is linked to the amount of free reaction sites for the oxidation reaction. This theory explains well the fact that a high concentration of doping changes the Fermi level and increases the number of vacancies and thus the oxidation rate. However, it must be stressed that nitrogen is the only species where a reduction of the kinetics is observed ${ }^{19,42,44}$. All the other dopants increase (at various degrees) the reaction rate. Thus, the Ho and Plummer approach can not be applied to the case where $\mathrm{N}$ is incorporated at the interface by oxynitridation or implantation.

The physical origin of the self-limited oxidation mechanism is still not clear. However some reasonable assumptions can be explained by the kinetics reduction. Nitrogen defects in Si have been studied for many years and it is generally accepted that most of the defects created exist in neutral forms. A possible shift of the Fermi level like in the Ho and Plummer theory has therefore to be excluded. A more direct mechanism has to be considered. The Ab-initio simulations reported in the paper of Goss et al. underline the strong interaction between $\mathrm{N}$ (mainly nitrogen pairs) and vacancies ${ }^{45}$. The $\mathrm{N}$ incorporation at vacancies sites is a plausible explanation to the retardation mechanism since this effect lowers the available free reaction site for the classical oxidation process. A different approach from Ho and Plummer model must be considered in order to take the influence of $\mathrm{N}$ into account. 


\section{Introduction of the influence of nitrogen in the reaction rate expression}

Based on the previous analysis, it is assumed that the reaction rate is proportional to the concentration of reactive sites $\mathrm{C}_{g r}$ :

$$
k=k_{0} \exp \left(\frac{-E_{A}}{k_{b} T}\right) C_{g r}
$$

The free reacting sites concentration $\left(\mathrm{C}_{g r}\right)$ is thus directly related to the nitrogen species SiN. From the previous section describing the interaction between atomic nitrogen and silicon, it can be deduced that the presence of SiN specie is governed by the competition between nitridation ${ }^{46}$ and nitrogen removal ${ }^{40}$ :

$$
\frac{\partial n_{[S i N]}}{\partial t}=k_{\left[N^{*}\right]} n_{\left[N^{*}\right]} n_{[S i]}-k_{\text {removal }} n_{\left[O^{*}\right]} n_{[S i N]}
$$

$\mathrm{C}_{g r}$ follows an equivalent equation with generation and recombinaition terms. The recombination can be attributed to the nitridation reaction which removes growing sites while the generation part is associated to the nitrogen removal reaction and the generation of defects during the oxidation process ${ }^{47}$ :

$$
\frac{\partial C_{g r}}{\partial t}=G-R
$$

Assuming that the generation term has the same activation energy as the reaction rate of a dry oxidation, leads to equation (21) :

$$
G=G_{0} \exp \left(\frac{-E_{A}}{K_{B} T}\right)
$$

and the recombinaison terms to be proportional to the concentration of growth sites $\mathrm{C}_{g r}$ :

$$
R=\frac{C_{g r}}{\tau} .
$$

At the beginning of the oxyntridation process, since no SiN species are present, the following expression is obtained:

$$
\begin{aligned}
C_{g r}= & a_{0} \exp \left(\frac{-E_{A^{\prime}}}{k_{b} T}\right) \\
& +b_{0} \exp \left(\frac{-t}{\tau}\right) \exp \left(\frac{-E_{A^{\prime}}}{k_{b} T}\right)
\end{aligned}
$$


where $\mathrm{a}_{0}, \mathrm{~b}_{0}, \mathrm{E}_{A^{\prime}}, \tau$ are new parameters. This equation leads to the final expression equation (24) for reaction $k$ in the case of $\mathrm{N}_{2} \mathrm{O}$ :

$$
k=a_{0} \exp \left(\frac{-E_{A^{\prime}}}{k_{b} T}\right)\left[1+b_{0} \exp \left(\frac{-t}{\tau}\right)\right]
$$

\section{Calibration}

The compact model needs the following four parameters: $\mathrm{E}_{A^{\prime}}, \mathrm{a}_{0}, \mathrm{~b}_{0}$ and $\tau$. The parameters were adjusted on the oxidation kinetics of Ting et al. ${ }^{13}$ reported in the next section. Several numerical procedures have been tested (least square methods, simulated annealing) in order to determine the best parameters set. Most of the fits lead to unphysical parameters and, to reach a physical solution in the initial regime, the value of the reaction rate $k$ should be close to that used for dry oxidation ${ }^{32}$. Reasonable physical parameters were reported in the next table III in order to describe the reaction rate in presence of $\mathrm{N}$. The characteristic time $\tau$ which can be viewed as the time step necessary to incorporate a sufficient amount of N. It was obtained by the calibration step for a given temperature range. An Arrhenius law given by the next equation (25) was observed :

$$
\frac{1}{\tau}=86.96 \exp \left(\frac{-1}{k_{b} T}\right)
$$

With the help of equation (25) and the parameters given in table III, the reaction rate given in equation (24) was calculated in the temperature range considered. The mathematical system is made of three coupled equations (16). This system is numerically solved using a Crank-Nicolson method ${ }^{28}$.

\section{COMPARISON BETWEEN THE COMPACT MODEL AND EXPERIMENTAL RESULTS}

It is difficult to assess the physical validity of an oxidation model by simply considering the quality of the agreement between the theoretical oxidation kinetics and some experimental data as previously elegantly underlined by Blanc ${ }^{48}$. A particular attention on the physical relevance of the kinetics parameters should be paid to ${ }^{49}$. On the other hand, it is often needed to evaluate the practical capability and the limits of a oxidation model in order to 
describe the experimental oxidation kinetics specially in the ultra-thin regime. The compact model was compared to several experimental kinetics available in the literature. A particular attention was paid to the kind of furnace (rapid thermal annealing or classical). It was claimed experimentally that the nitrogen incorporation or the $\mathrm{N}$ profile is highly dependent on gas process parameters such as input flow rate ${ }^{29}$ or on the type of furnace used ${ }^{50}$.

\section{A. Test with rapid thermal annealing experiments}

The minimal model was compared to the experiments of Ting et al. ${ }^{13}$. The experiments were performed with a commercial lamp-heated rapid thermal processor. The oxidation temperature ranged from $950^{\circ} \mathrm{C}$ to $1200^{\circ} \mathrm{C}$ with increments of $50^{\circ} \mathrm{C}$ and oxidation times from 10 to $300 \mathrm{~s}$. It has been estimated that the average concentration in the grown oxide are less than $4 \%$ at the interface. The experimental kinetics is firstly characterized by a short fast initial regime and next followed by a strongly limited oxidation range. To facilitate the comparison between the model and these experiments, the simulated kinetics was shifted vertically in order to match the experimental oxide thickness at the end of the temperature ramp-up. The shift is between $1.5 \mathrm{~nm}$ for the lowest temperature up to 2.4 $\mathrm{nm}$ for $1150^{\circ} \mathrm{C}$. The comparison between the model and these experiments are in excellent agreement from the previous calibration. As shown in the figure (9), the fast initial time for high temperature is well described. A nice agreement is obtained in the self-limited oxidation regime where oxidation is strongly reduced by the nitrogen incorporation. Left alone, the initial oxide thickness concern, the trends and the variations of oxide growth are well described. Next, the comparison with the experimental kinetics from Yoon et al. ${ }^{51}$ was undertaken. The growth of ultra-thin (3-10 nm) oxynitride films was performed using a specific designed furnace (vertical gas flow and rotation of the substrate). The authors report an excellent uniformity for the oxides grown (5\%) since the $\mathrm{N}_{2} \mathrm{O}$ oxidation is more sensitive to the process variation. The oxidation times are much shorter here between [20100] $\mathrm{s}$ and the self-limited regime is then less visible. The agreement with the model remains very good if it is assumed that the initial temperature ramp-up creates an initial oxynitride of about $2.5 \mathrm{~nm}$. 


\section{B. Test with classical furnace experiments}

Next, the model has been compared to the experimental work of Soleimani et al. ${ }^{52}$. These oxynitridation experiments were undertaken in an ambient of pure $\mathrm{N}_{2} \mathrm{O}$ at a pressure of 500 Torr and three relatively low temperatures $\left(885^{\circ} \mathrm{C}, 935^{\circ} \mathrm{C}\right.$ and $\left.975^{\circ} \mathrm{C}\right)$. Much larger oxidation times are required here from $20 \mathrm{~min}$ up to $120 \mathrm{~min}$ in order to grow a significant oxide thickness. Only the experimental kinetics with the lowest initial oxide thickness (1.5 nm) was considered $^{53}$. An overall good agreement is observed between the theory and experiments. The main discrepancy is observed for the last point at $935^{\circ} \mathrm{C}$ but the error remains lower than $1 \mathrm{~nm}$ for the other points. Finally, the experiments of Bhat et al. ${ }^{54}$ have also been studied. Here, the oxidation experiments were performed in a classical temperature heated furnace. A dry ambient, during the temperature ramp-up, has been used to prevent an initial surface nitridation. The experiments are very similar to those of Soleimani et al. with large oxidation times and a temperature around $1000^{\circ} \mathrm{C}$. Again an overall good agreement is obtained and the trends are in agreement with the experiments. The only exception is for the highest temperature where the model predicts a more self-limited oxidation regime. However, it should be kept in mind that the $\mathrm{N}$ diffusion/out-diffusion could not be neglected for these long oxidation times.

\section{CONCLUSION}

Some progress in the modelling of $\mathrm{N}_{2} \mathrm{O}$ oxynitridation process is reported. The steady state concentration of $\mathrm{O}_{2}$ and $\mathrm{NO}$ was estimated through the modelling of the gas phase decomposition. A general model based on the reaction rate approach which described the large competition between nitridation and nitrogen removal was specified. A minimal model where only the oxidation with $\mathrm{O}_{2}$ is simulated was implemented and calibrated. The influence of molecular nitrogen in the reaction rate has been successfully incorporated. Although the minimal model was adjusted on rapid thermal annealing experiments, it has been able to give a correct trend both in the thin and the limited regime observed for a longer oxidation. The kinetics predicted by the model is in good agreement with several experimental works. Current limits and a possible strategy to access to a complete modelisation of the $\mathrm{NO}, \mathrm{N}_{2} \mathrm{O}$ oxynitridation processes and to the $\mathrm{N}$ profile have been discussed. 


\section{ACKNOWLEDGMENTS}

The author thanks Wilfried Lerch for suggesting the industrial interest of $\mathrm{N}_{2} \mathrm{O}$ oxynitri-

dation. This work was supported by the European Commission with the former European project FRENDTECH (IST-2000-30129). 


\section{REFERENCES}

1 "Tsmc pushes out high-k in 28-nm rollout," http://http://www.eetimes.com/news/ semi/showArticle.jhtml?articleID $=210604347$.

${ }^{2}$ H. Chung, J. Niess, W. Dietl, G. Roters, W. Lerch, Z. Nenyei, A. Ludsteck, J. Schulze,

I. Eisele, K. Wieczorek, et al., Semiconductor international 27, 73 (2004).

${ }^{3}$ H. Fukuda, M. Yasuda, T. Iwabucchi, and S. Ohno, IEEE Electron Devices Letters 12, 587 (1991).

${ }^{4}$ A. B. Joshi, G. Yoon, G. Q. Lo, and D.-L. Kwong, IEEE Electron Devices 40, 1437 (1993).

${ }^{5}$ H. Hwang, W. Ting, D. L. Kwong, and J. Lee, IEEE Electron Devices 12, 495 (1991).

${ }^{6}$ A. Philipossian and D. B. Jackson, Journal of The Electrochemical Society 139 (1992).

${ }^{7}$ T. Hori, H. Iwasaki, T. Ohmura, and Y. Yoshioka, Journal of Applied Physics 65, 629 (1989).

${ }^{8}$ Y. Okada, P. J. Tobin, K. G. Reid, R. I. Hegde, B. Maiti, and S. A. Ajuria, IEEE Electron Devices 41, 1608 (1994).

${ }^{9}$ R. I. Hedge, P. J. Tobin, K. G. Reid, B. Maiti, and S. Ajuria, Journal of Applied Physics 66 (1995).

${ }^{10}$ M. Bhat, L. K. Han, D. Wristers, J. Yan, D. L. Kwong, and J. Fulford, Journal of Applied Physics 66, 1225 (1995).

${ }^{11}$ Z.-Q. Yao, H. B. Harrisson, S. Dimitrijev, and Y. T. Yeow, IEEE Trans. on Electron Devices Letters 15 (1994).

${ }^{12}$ H. Hwang, W. Ting, B. Maiti, D.-L. Kwong, and J. Lee, Applied Physics Letters 57, 1010 (1990).

${ }^{13}$ W. Ting, H. Hwang, J. Lee, and D. L. Kwong, Journal of Applied Physics 70, 1072 (1991).

${ }^{14}$ G. Q. Lo, W. Ting, J. Ahn, and D. L. Kwong, IEEE Electron Devices Letters 13, 111 (1992).

${ }^{15}$ J. Ahn, W. Ting, and D. L. Kwong, IEEE Electron Devices Letters 13, 117 (1992).

${ }^{16}$ A. Bauer and E. Burte, Microelectronics Journal 27, 667 (1996).

${ }^{17}$ B. E. Deal and A. S. Grove, J. Appl. Phys. 36, 3770 (1965).

${ }^{18}$ S. Dimitrijev, H. B. Harrison, and D. Sweatman, IEEE Trans. on Electron Devices 43 (1996). 
${ }^{19}$ H. R. Soleimani, B. S. Doyle, and A. Philipossian, Journal Electrochemical Society 142 (1995).

${ }^{20}$ A. Morales-Acevedo, G. Santana, and J. Carillo-Lopez, Journal of The Electrochemical Society 148 (2001).

${ }^{21}$ E. C. Carr, K. A. Ellis, and R. A. Buhrman, Applied Physics Letters 66, 1492 (1995).

${ }^{22}$ C. S. Mian and L. S.-Y. Flora, Solid-State Electronics 43, 1997 (1999).

${ }^{23}$ E. P. Gusev, H. C. Lu, E. Garfunkel, T. Gustafsson, M. L. Green, D. Brasen, and W. N. Lennard, Journal of Applied Physics 84, 2980 (1998).

${ }^{24}$ S. S. Dang and C. G. Takoudis, Journal of Applied Physics 86, 1326 (1999).

${ }^{25}$ M. J. Hartig and P. J. Tobin, Journal of The Electrochemical Society 143, 1753 (1996).

${ }^{26}$ A. Gupta, S. Toby, E. P. Gusev, H. C. Lu, Y. Li, M. L. Green, T. Gustafsson, and E. Garfunkel, Progress in Surface Science 59, 103 (1998).

${ }^{27}$ K. A. Ellis and R. A. Buhrman, IBM Journal of Research and Development 43 (1999).

${ }^{28}$ W. Press, S. A. Teukolsky, W. T. Vetterling, and B. P. Flannery, Numerical Recipes in Fortran 77, The art of scientific computing (Cambridge University Press, 1986).

${ }^{29}$ P. J. Tobin, Y. Okada, S. A. Ajuria, V. Lakhotia, W. A. Feil, and R. I. Hedge, Journal of Applied Physics 75, 1811 (1994).

${ }^{30}$ R. M. C. de Almeida and I. J. R. Baumvol, Phys. Rev. B 62, R16255 (2000).

${ }^{31}$ R. M. C. de Almeida, I. J. R. Baumvol, J. J. Ganem, I. Trimaille, and S. Rigo, Journal of Applied Physics 95, 1770 (2004).

${ }^{32}$ C. Krzeminski, G. Larrieu, J. Penaud, E. Lampin, and E. Dubois, Journal of Applied Physics 101, 064908 (2007).

${ }^{33}$ In case of an incomplete decomposition, atomic oxygen for example $\mathrm{O}^{*}$ should be introduced.

${ }^{34}$ It corresponds to the different silicon-nitrogen species.

${ }^{35}$ This assumption can not be done for nano-object oxidation, see for example.

${ }^{36}$ B. A. F. Rochet and S. Rigo, J. Electrochem. Soc: Solid State Science and Technology 131, 914 (1984).

${ }^{37}$ C.-J. Han and C. R. Helms, J. Electrochem. Soc. 134, 1297 (1987).

${ }^{38}$ Y. Ishikawa, Y. Takagi, and I. Nakamichi, Japanese Journal of Applied Physics 28, L1453 (1989).

39Z. Yao, Journal of Applied Physics 78, 2906 (1995). 
${ }^{40}$ N. S. Saks, D. I. Ma, and W. B. Fowler, Journal of Applied Physics 67, 374 (1995).

${ }^{41}$ E. Antoncik, Applied Physics A 58, 117 (1994).

${ }^{42}$ C. P. Ho and J. D. Plummer, J. Electrochem. Soc.: solid state science and technology 126, 1516 (1979).

${ }^{43}$ C. P. Ho and J. D. Plummer, J. Electrochem. Soc.: solid state science and technology 126, $1523(1979)$.

${ }^{44}$ C. R. Fritzsche and W. Rothemund, Journal of Electrochemical Society 120, 1603 (1973).

${ }^{45}$ J. P. Goss, I. Hahn, R. Jones, P. R. Briddon, and S. Oberg, Phys. Rev. B 67, 045206 (2003).

${ }^{46}$ V. A. Gritsenko, H. Wong, W. M. Kwok, and J. B. Xu, Journal of Vacuum Science \& Technology B: Microelectronics and Nanometer Structures 21, 241 (2003).

${ }^{47}$ D. Skarlatos, D. Tsoukalas, L. F. Gilles, and A. Claverie, Appl. Phys. Lett. 87 (2000).

${ }^{48}$ J. Blanc, Philosophical Magazine Part B 55, 685 (1987).

${ }^{49}$ P. Roura and J. Farjas, Phys. Rev. B 74, 127301 (2006).

${ }^{50}$ E. C. Carr and R. A. Buhrman, Applied Physics Letters 63, 54 (1993).

${ }^{51}$ G. W. Yoon, A. B. Joshi, J. Ahn, and D. L. Kwong, Journal of Applied Physics 72, 5706 (1992).

${ }^{52}$ H. R. Soleimani, A. Philipossian, and B. Doyle, Technical Digest of the 1992 IEDM conference, 631 (1992).

${ }^{53}$ Various initial oxide thickness grown in dry conditions have been considered in the study of Soleimani et al. and only a vertical shift of the various $\mathrm{N}_{2} \mathrm{O}$ kinetics has been observed.

${ }^{54}$ M. Bhat, H. Jia, and D. L. Kwong, Journal of Applied Physics 78 (1995) 
Figure 1. : Variation of the reaction rate coefficient $R_{1}$ using the parameters from table $I$.

Figure 2. : Evolution of the different species during gas phase decomposition at $1200^{\circ} \mathrm{C}$.

Figure 3. : The evolution of the steady state concentration of the three species resulting from the decomposition $\left(\mathrm{N}_{2} \mathrm{O}, \mathrm{O}_{2}, \mathrm{NO}\right)$ in function of the furnace temperature.

Figure 4. : The half-time life of the $\mathrm{N}_{2} \mathrm{O}$ molecule is simulated as a function of the furnace temperature. The decomposition of $\mathrm{N}_{2} \mathrm{O}$ is less effective at low temperatures (less than $0.1 \mathrm{~ms}$ at $1200^{\circ} \mathrm{C}$ ).

Figure 5. : Focus on the evolution of the NO concentration in function of the furnace temperature.

Figure 6. : Schematic view of the system model. The profile of $\mathrm{Si}, \mathrm{SiO}_{2}$ and nitrogen concentration are presented and lead to the definition of two different layers: the oxynitride $\mathrm{SiO}_{x} \mathrm{~N}_{y}$ and the $\mathrm{Si}$ part.

Figure 7. : General strategy proposed in order to simulate the $\mathrm{N}_{2} \mathrm{O}$ oxynitridation step. Oxidation $\mathrm{O}_{2}$ and nitridation and oxidation by NO can be viewed as parallel atomic process.

Figure 8. : Variation of the characteristic time $\tau$ with the furnace temperature. $\tau$ varies from $40 \mathrm{~s}$ at $1150^{\circ} \mathrm{C}$ up to $225 \mathrm{~s}$ at $800^{\circ} \mathrm{C}$. The values are compatible with the time necessary to incorporate a sufficient amount of nitrogen to strongly reduce the oxidation kinetics.

Figure 9. : Comparison between the minimal model and the kinetics of Ting et al.. The oxidation kinetics is clearly limited by the nitrogen incorporation after a time around $50 \mathrm{~s}$.

Figure 10. : Comparison between the minimal model and the kinetics of G. W Yoon et al. ${ }^{51}$. 
Figure 11. : Comparison between the minimal model and the kinetics of Philipossian et al.

Figure 12. : Comparison between the minimal model and the kinetics of Bhat et al. ${ }^{54}$. 
TABLES 
Table I. Arrhenius parameters for reaction $\left(\mathrm{R}_{1}\right)$ governing the $\mathrm{N}_{2} \mathrm{O}$ decomposition. The units for the pre-exponential factor are $\mathrm{cm}^{3} \cdot \mathrm{mol}^{-1} \cdot \mathrm{s}^{-1}$. Activation energies are given in $\mathrm{eV}$.

\begin{tabular}{ccc}
\hline \hline $\mathrm{T}(\mathrm{K})$ & $\mathrm{k}_{01}$ & $\mathrm{E}_{1}(\mathrm{eV})$ \\
\hline$[1300-2500]$ & $5 \times 10^{+14}$ & 2.5 \\
{$[1050-1300]$} & $1.1 \times 10^{+13}$ & 2.07 \\
{$[900-1050]$} & $2.7 \times 10^{+15}$ & 2.57 \\
\hline \hline
\end{tabular}

Table II. Arrhenius parameters for the other reactions $\left(\mathrm{R}_{2}\right) \rightarrow\left(\mathrm{R}_{8}\right)$. The units for the preexponential factor are $\mathrm{cm}^{3} \cdot \mathrm{mol}^{-1} \cdot \mathrm{s}^{-1}$ for second order reactions $\left(\mathrm{R}_{2}, \mathrm{R}_{3}, \mathrm{R}_{6}, \mathrm{R}_{8}\right)$ and $\mathrm{cm}^{6}$. $\mathrm{mol}^{-2} \cdot \mathrm{s}^{-1}$ for third order reactions $\left(\mathrm{R}_{4}, \mathrm{R}_{5}\right)$.

\begin{tabular}{ccc}
\hline \hline Reaction & $\mathrm{k}_{0 x}$ & $\mathrm{E}_{x}(\mathrm{eV})$ \\
\hline$\left(\mathrm{R}_{2}\right)$ & $1.0 \times 10^{+13}$ & 0.078 \\
$\left(\mathrm{R}_{3}\right)$ & $1.0 \times 10^{+14}$ & 1.210 \\
$\left(\mathrm{R}_{4}\right)$ & $1.0 \times 10^{+14}$ & 1.210 \\
$\left(\mathrm{R}_{5}\right)$ & $1.0 \times 10^{+15}$ & -0.081 \\
$\left(\mathrm{R}_{6}\right)$ & $1.0 \times 10^{+13}$ & 0.026 \\
$\left(\mathrm{R}_{7}\right)$ & $0.0 \times 10^{+13}$ & 0.026 \\
$\left(\mathrm{R}_{8}\right)$ & $2.0 \times 10^{+12}$ & 1.160 \\
\hline \hline
\end{tabular}

Table III. Parameters for the reaction rate expression of the compact model.

\begin{tabular}{cc}
\hline \hline $\mathrm{E}_{A^{\prime}}$ & $1.42 \mathrm{eV}$ \\
\hline $\mathrm{a}_{0}$ & $10^{+06} \mathrm{~nm} / \mathrm{s}^{-1}$ \\
$\mathrm{~b}_{0}$ & 11 \\
\hline \hline
\end{tabular}


FIGURES 


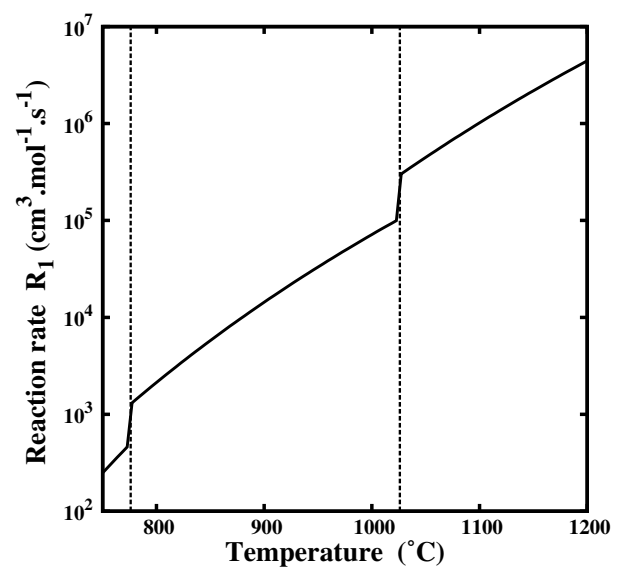




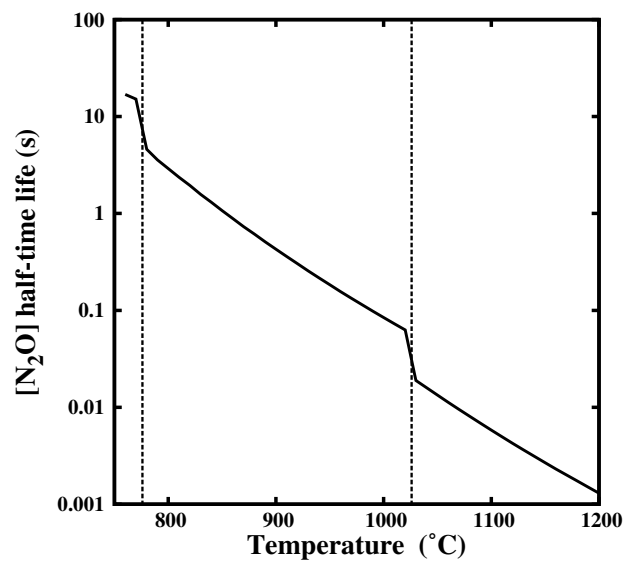


$\mathrm{N}_{2} \mathrm{O}$ Gas phase decomposition
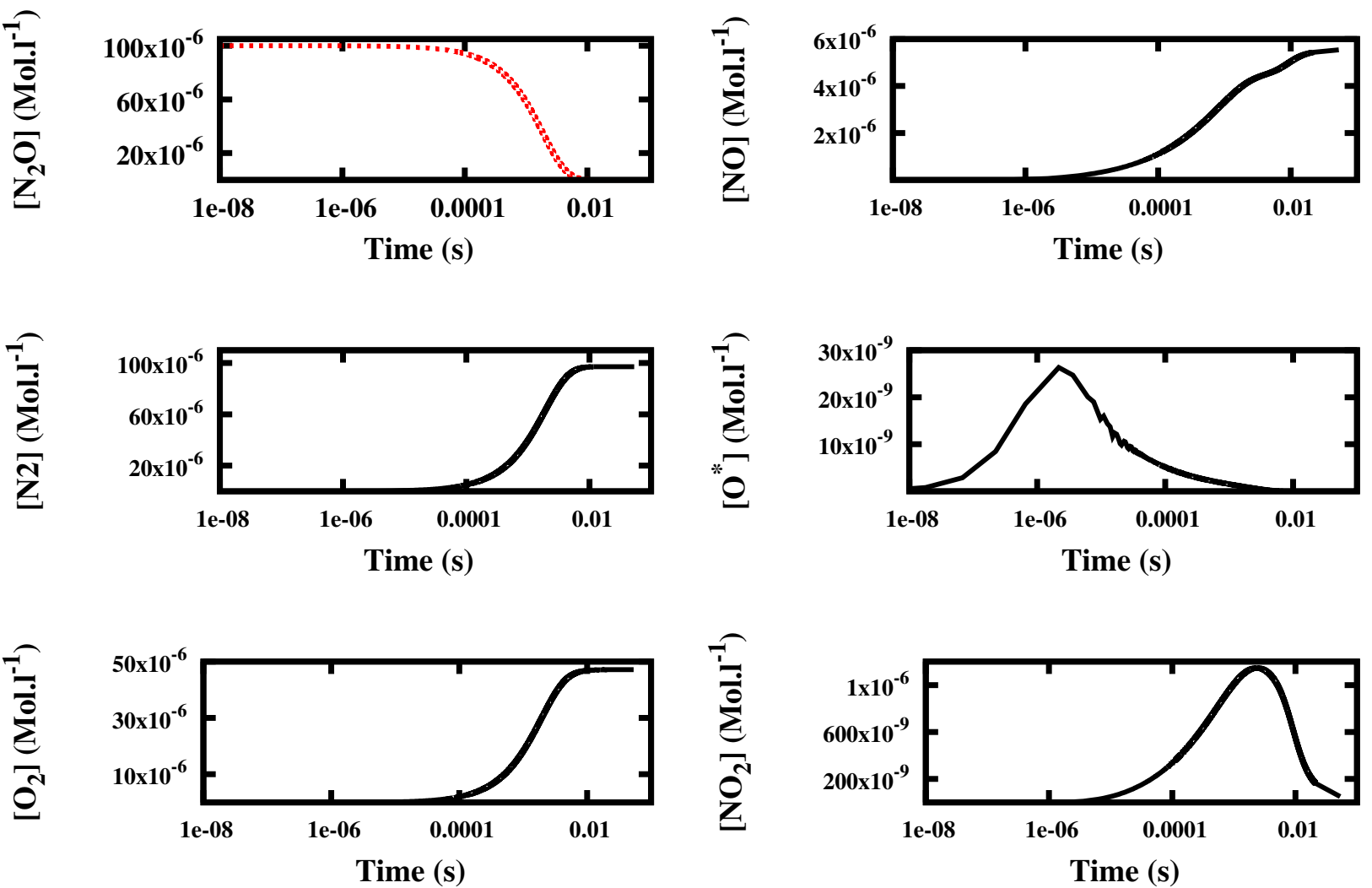


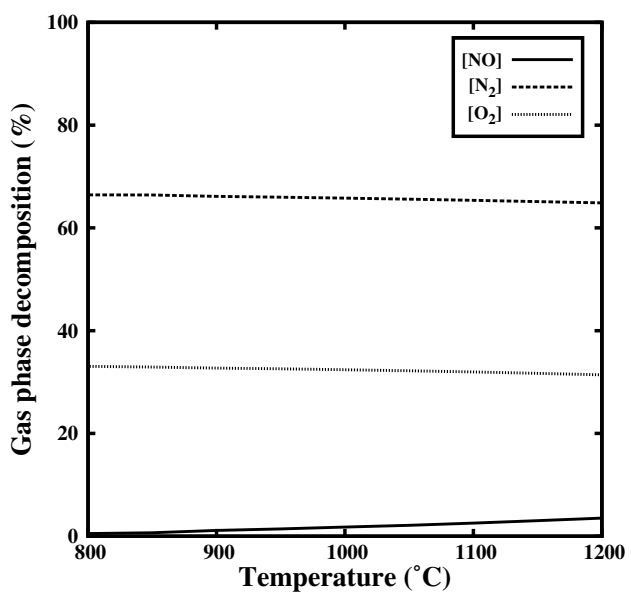




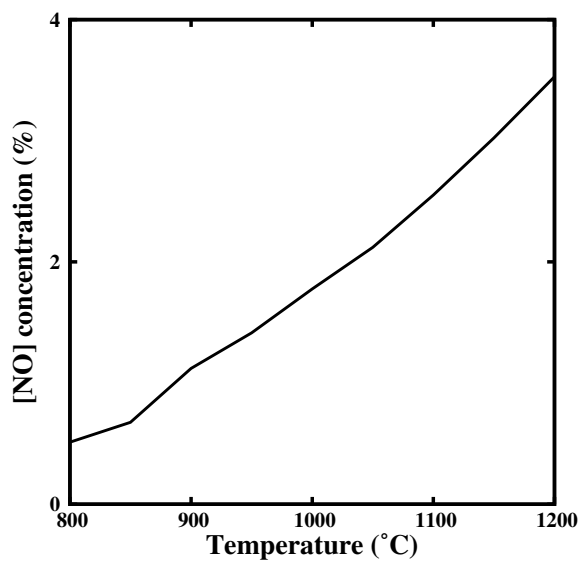




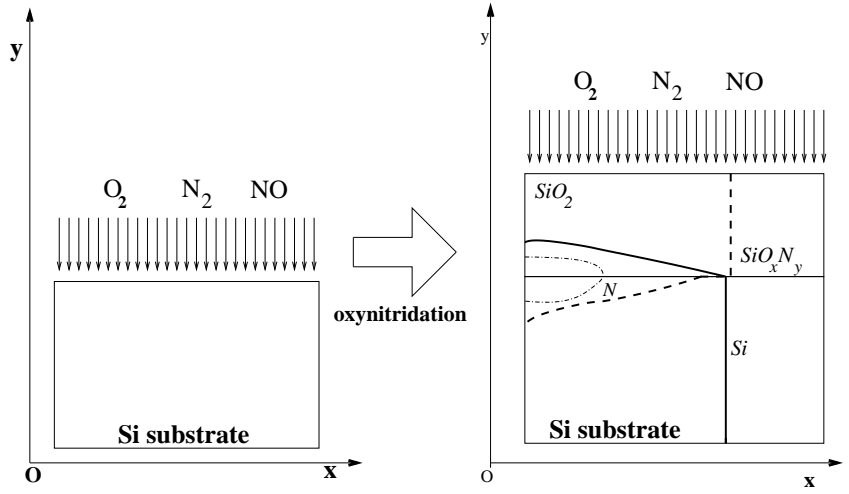




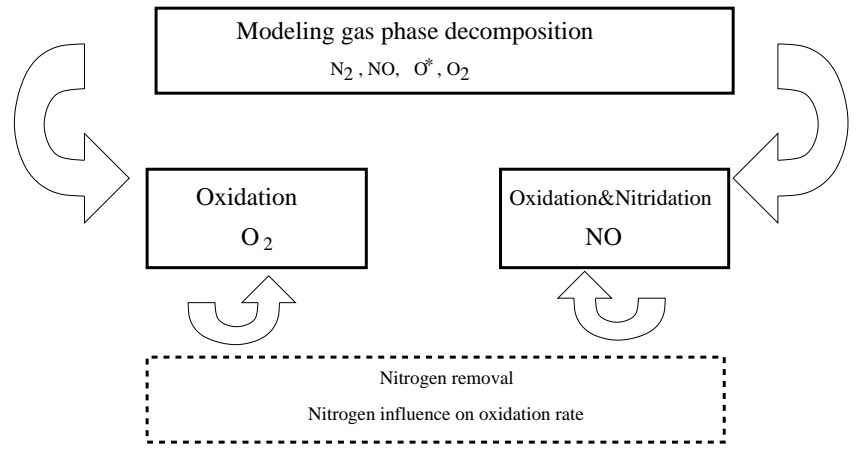




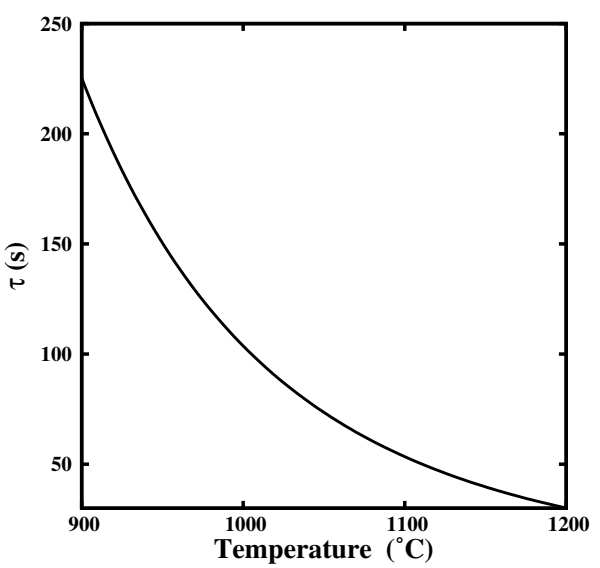




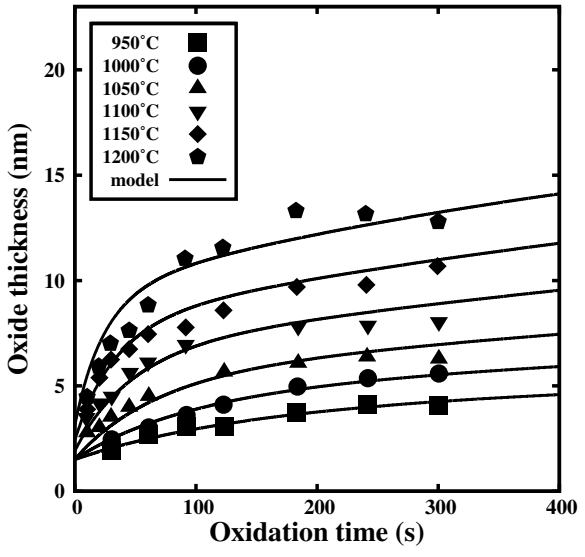




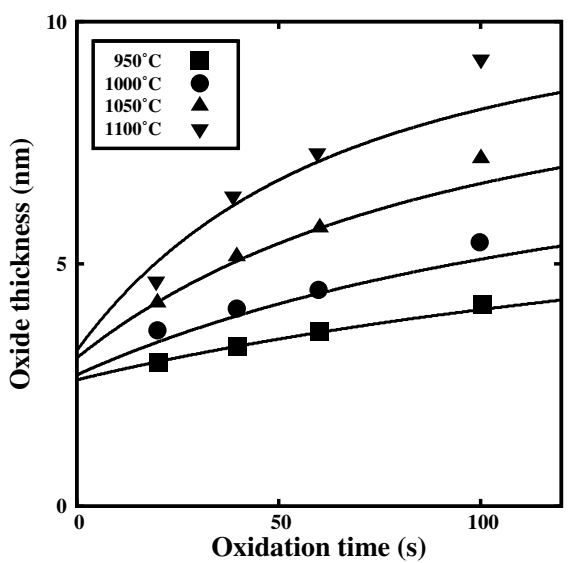




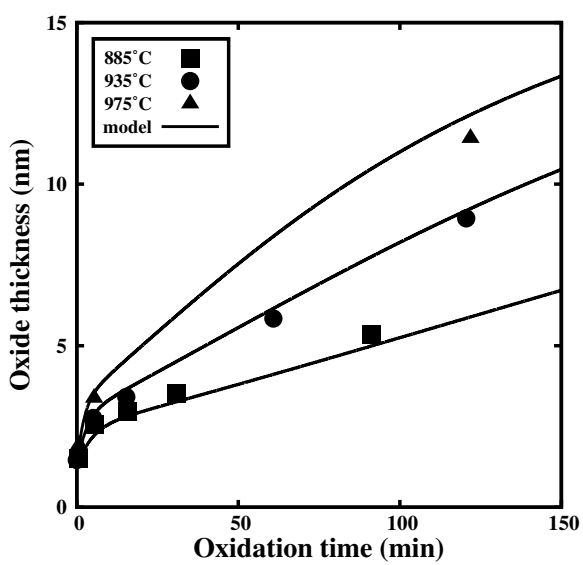




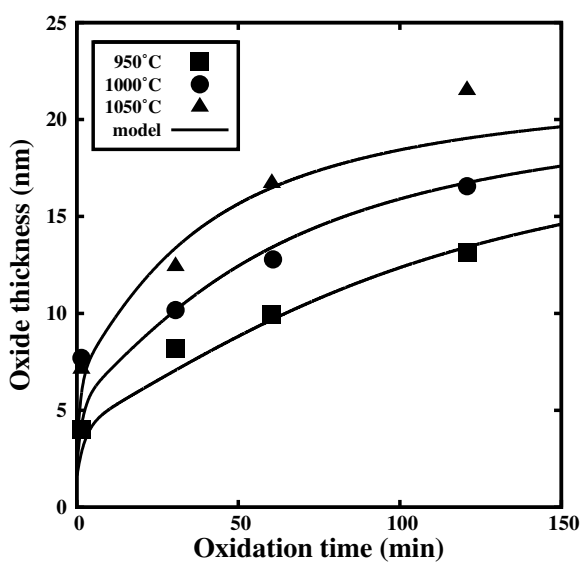

